\title{
Field Evaluation of Rice Accessions against Yellow Stem Borer, Scirpophaga Incertulas Wlk.
}

\author{
Anil Varma Nalla", D. Adiroubane, K. Kumar, S. Nadaradjan \\ Pandit Jawaharlal Nehru College of Agriculture and Research Institute, Karaikal- 609 603, U.T. Of Puducherry \\ *Corresponding Author: Anil Varma Nalla, Pandit Jawaharlal Nehru College of Agriculture and \\ Research Institute, Karaikal- 609 603, U.T. Of Puducherry
}

\begin{abstract}
Field evaluation of 196 rice accessions were carried at Pandit Jawaharlal Nehru College of Agriculture and Research Institute, Karaikal, for identifying the resistant entries against yellow stem borer, Scirpophaga incertulas. Accessions were screened for stem borer at vegetative and reproductive stages. At vegetative stage (dead heart) during Kharif 2011, five entries were identified as resistant entries viz., entry Nos. 40 (OR 2324-8), 160 (RTN 62-6-7-1), 140 (CR 2698), 60 (HUR-913) and 150 (CN 1561-70-19-35-9$M L D 1)$. At reproductive stage (white ear) four entries were identified as moderately resistant viz., entry Nos. 40 (OR 2324-8), 160 (RTN 62-6-7-1), 70 (R 1138-688-3-533-1) and 140 (CR 2698).
\end{abstract}

Keywords: Field evaluation, rice accessions, yellow stem borer.

\section{INTRODUCTION}

Rice (Oryza sativa L.) is an important and staple food crop for more than two third population of India. Rice crop plays a vital role in our national food security and is a means of livelihood for millions of rural households. Worldwide, rice is grown over 153.766 million ha (Maclean et al., 2002) and India is the second highest producer next to China (http: faostat. faoorg/faostat/ collections). India ranks first in area under rice (43.77 million hectares) and second in production (96.43 million tons). The productivity of rice is low in India $\left(2,203 \mathrm{~kg} \mathrm{ha}^{-1}\right)$ when compared to the world average and leading rice growing countries (DES, 2008).

Among various insect species attacking rice, stem borers are key pests as they infests the plant right from seedling to maturity and worldwide in distribution (Pathak, 1975). The larvae of these borers cause dead hearts during vegetative stage resulting in loss of productive tillers and also results in white ear damage at crop maturity phase resulting chaffy grain. In India yellow stem borer, Scirpophaga incertulas has assumed the number one pest status as national pest (Pasalu et al., 2002). The extent of damage caused by the yellow stem borer in rice ranged from 3 to 95 per cent (Ghose et al., 1960).

In view of above background, an attempt was made to screen a few rice germplasm lines to assess the extent of resistance to yellow stem borer, $S$. incertulas.

\section{Materials AND Methods}

One ninty six rice accessions were taken for screening received from Directorate of Rice Research (DRR), Hyderabad with susceptible checks Suraksha and TN-1 (Table 1). Seedlings were transplanted in main field with two replications after 25 days after sowing (DAS). Standard evaluation system of rice was followed for screening the rice accessions which was developed by IRRI (1985) for yellow stem borer, Scirpophaga incertulas.

Fertilizers were applied according to the recommendation. Standing water was maintained continuous to a height of 2 to $5 \mathrm{~cm}$ throughout the crop season by irrigating the field on need basis. Weeds were manually removed from experimental field to avoid crop-weed competition during crop period.

Assessment has been taken based on damage symptom for stem borer at two stages such as vegetative stage (30 DAT) and reproductive stage (70 DAT). For each entry five hills were selected randomly in each replication. Damage symptom at 30 DAT is the dead heart and its number was recorded in all 
entries. Per cent stem borer damage (Heinrichs et al., 1985) was estimated by counting the number of tillers and damaged tillers as follows.

No. of damaged tillers (Dead hearts/White ears)

$\%$ dead hearts $/$ white ears $=$ X 100

Total No. of tillers

Percentage of dead heart/white ears was converted to D

$\%$ dead hearts/ white ears in test entry

$\mathrm{D}=$

$\%$ dead hearts / white ears in the susceptible check

(Mean of two susceptible checks)

$\mathrm{D}$ is converted to a $0-9$ scale

\begin{tabular}{|c|c|c|}
\hline Scale & D & Status \\
\hline 0 & No Damage & Highly Resistant \\
\hline 1 & $1-20 \%$ & Resistant \\
\hline 3 & $21-40 \%$ & Moderately Resistant \\
\hline 5 & $41-60 \%$ & Moderately susceptible \\
\hline 7 & $61-80 \%$ & Susceptible \\
\hline 9 & $81-100 \%$ & Highly Susceptible \\
\hline
\end{tabular}

The means of the five hills were taken for tabulation.

\section{RESUlTS \& DiscusSiON}

One hundred and ninety six entries including two susceptible checks (TN 1 \& Suraksha) were screened to find out the entries exhibiting resistance for rice stem borer, Scirpophaga incertulas during vegetative stage and reproductive stage. The seedlings were evaluated during vegetative stage at 30 DAT in Kharif 2011. Out of the $196(194+2)$ entries screened, five entries were graded as resistant, 51 were found moderately resistant, 94 entries were rated as moderately susceptible, 39 entries as susceptible and five entries were identified as highly susceptible (Fig 1). Panigrahi and Rajamani (2010) screened 118 deep water rice accessions and found 64 entries as resistant at vegetative stage.

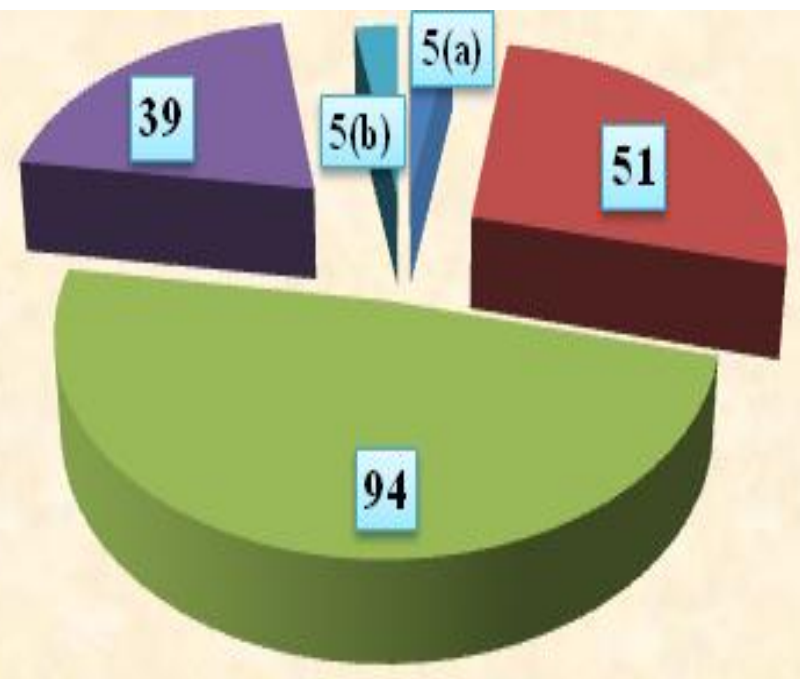

(5a) Resistant; (51) Moderately resistant; (94) Moderately susceptible; (39) Susceptible; (5b) Highly susceptible

Fig1. Incidence of stem borer at vegetative stage

During reproductive stage, no entry was found resistant, four entries were moderately resistant, 64 entries were found moderately susceptible, 94 entries were rated as susceptible and 32 were found as highly susceptible (Fig 2). Out of the 196 entries no entry was found to be resistant at this stage but Sujay Pandey and Choubey (2011) screened 60 germplasm and found 35 were resistant. Singh and 
Pandey (1997) screened forty one rice germplasm and found ten entries as resistant at vegetative stage and one entry at reproductive stage.

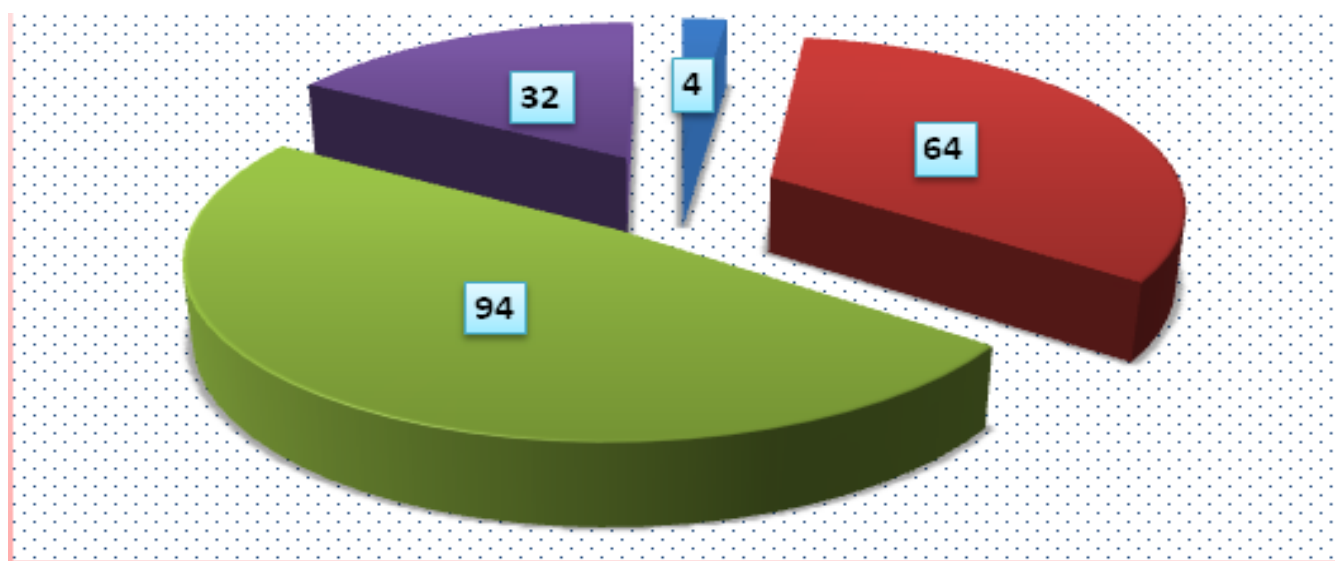

(4) Moderately resistant; (64) Moderately susceptible; (94) Susceptible; (32) Highly susceptible

Fig2. Incidence of stem borer at reproductive stage

During Kharif 2011, dead heart by stem borers ranged from 4.42-41.9 per cent. Susceptible check Suraksha and TN 1 had 39.4 per cent and 41.9 per cent dead hearts respectively during vegetative stage, while the per cent white ears were 8.04 per cent and 8.32 per cent. The per cent white ears recorded from 196 entries ranged from 1.23 per cent to 8.32 per cent. The least incidence was observed in entry No. 40 (OR2324-8) with 4.42 per cent dead heart which also simultaneously shown low damage of 1.23 per cent white ears.

The results obtained during the investigation showed that some of the entries exhibited low incidence with dead hearts did not prove themselves resistance with low infestation exhibiting minimum white ears. Entry No. 70 (R 1138-688-3-533-1) was found to be moderately susceptible with 16.37 per cent dead heart during vegetative stage while in the reproductive stage it was found to be moderately resistant with 1.82 per cent white ears. This finding is in conformity with the findings of earlier workers (Pathak, 1964; Mathur and Chathurvedi, 1978; Srivastava, 1979; Chandra Mohan and Chelliah, 1983; Singh and Pandey; 1997) who reported that the rice varieties resistant to yellow stem borer attack at vegetative stage are not necessarily resistant at reproductive stage.

Earlier various workers reported that resistant response in rice lines to stem borer with respect to different genotypes was based on damage scale as resistant, moderately resistant, susceptible, moderately susceptible and highly susceptible (Tiwary et al., 1988; Mishra et al., 1990; Gubbaiah and Revanna, 1993; Balasubramanian et al.,2000; Sarao et al.,2009; Padhi, 2009 and Rath et al.,2010).

\section{REFERENCES}

[1] Balasubramanian, V., S. Sadakathulla, M. Subramanian and S. Ramanathan, 2000. Screening Rice Entries of AICRIP in advanced yield trial for Resistance to Insect Pests of Rice. International Plant Resistance to Insects Newsletter, 26: 52.

[2] Chandramohan, N. and Chelliah, S. 1983. Rice resistance to yellow stem borer. Intern. Rice Res. Newsl., 8 (2): 8 .

[3] DES. 2008. Department of Economics and Statistics, Department of Agriculture, Government of India ( http://www.dacnet.nic.in ).

[4] Ghose, R.L.M., M.V. Ghatge and V. Subramaniam. 1960. Rice in India. Revised edition. Indian Council of Agricultural Research, New Delhi, 477p.

[5] Gubbaiah and Revanna, H.P. (1993). Curr. Res., 22: 14.

[6] Heinrichs, E. A., F. G. Medrano and H. Rapusas. 1985. (eds.). Genetic evaluation for insect resistance in Rice in Rice. IRRI, Los Banos, Philippines. Pp.103-279.

[7] Maclean, J.J., D.C. Dawe, B. Hardy and G.P. Hettel. 2002. Rice almanac. Los (Philippines);

[8] International Rice Research Institute, Bouake (Cote d'Ivoire); West Africa Rice Development

[9] Association, Cali (Colombia); International Center for Tropical Agriculture, Rome (Italy); Food and Agriculture Organization. $253 \mathrm{p}$.

[10] Mathur, K. C. and Chathurvedi, D. P. 1978. Screening of certain rice cultivars for resistance to stem borers at flowering stage. Oryza. 15 (2): 221-223. 
[11] Srivastava, S. K. 1979. Screening of indigenous rice cultivars against stem borer at flowering stage. Oryza. $16(2): 155$.

[12] Mishra B. K., B. K. Sontakke and H. Mohapatra. 1990. Antibiosis mechanism of resistance in rice varieties to yellow stem borer Scirpophaga incertulas Walker. Indian J. Plant. Prot. 18: 81-83.

[13] Padhi, G. 2009. Evaluation of selected lowland and medium land rice cultivars against Scirpophaga incertulas (Wlk.). Oryza. 46(2): 174-176.

[14] Panigrahi, D. and Rajamani, S. 2010. Evaluation of early medium land rice varieties against yellow stem borer, Scirpophaga incertulas (Wlk.) under irrigated condition. J. ent. Res., 34 B (3): 233-238.

[15] Pasalu, I.C., N.V. Krishnaiah, G.Katti and N.R.G.Varma.2002. IPM in rice. IPM News1.,45-55p.

[16] Pathak, M. D. 1964. Varietal resistance to rice stem borers at International Rice Research Institute. The major insect pests of the rice plant. The Jhons Hopkins Press, Baltimore, Maryland, 405-410.

[17] Pathak, M.D. 1975. Insect pests of rice. IRRI, Los Banos, Philippines, 68p.

[18] Rath, P.C., Meher, J. and Shubudhi, H.N. 2010. Field evaluation of improved rice genotypes against yellow stem borer. Oryza. 47 (4): 337-339.

[19] Sarao, P. S., Beant singh and Mahal, M. S. 2009. Relative susceptibility of rice genotypes to major insect pests of rice. Indian Journal of Entomology. 71(2): 155-159.

[20] Singh, S. S. and Pandey, V. 1997. Relative susceptibility of rice germplasm to yellow stem borer, Scirpophaga incertulas. Indian J. Ent., 59 (3): 257-262.

[21] Sujay Pandey and Choubey, M.N. 2011. Screening of different rice germplasms for resistance to yellow stem borer, Scirpophaga indertulas. Agric. Sci. Digest., 31 (2): 140-143.

[22] Tiwary, M. K., Singh. R. and Hameed S. F. 1988. Reaction of medium deep water rice varieties to stem borer. J. Ent. Res., 12 (2): 100-103.

Citation: Anil Varma Nalla, et.al., "Field Evaluation of Rice Accessions against Yellow Stem Borer, Scirpophaga Incertulas Wlk” International Journal of Research Studies in Agricultural Sciences (IJRSAS), 2020; 6(2), pp. 1-4, http://dx.doi.org/10.20431/2454-6224.0602004

Copyright: () 2020 Authors. This is an open-access article distributed under the terms of the Creative Commons Attribution License, which permits unrestricted use, distribution, and reproduction in any medium, provided the original author and source are credited. 